\title{
Abacavir Sulfate/Lamivudine/Zidovudine
}

National Cancer Institute

\section{Source}

National Cancer Institute. Abacavir Sulfate/Lamivudine/Zidovudine. NCI Thesaurus. Code C157473.

A fixed combination of abacavir sulfate, a nucleoside reverse transcriptase inhibitor (NRTI) analog of guanosine; lamivudine, an NRTI analog of cytidine; and zidovudine, an NRTI analog of thymidine, that may be used to treat human immunodeficiency virus (HIV) infection. Upon oral administration, abacavir, lamivudine, and zidovudine are phosphorylated into active metabolites that inhibit the HIV reverse transcriptase (RT) enzyme competitively and act as a chain terminator of DNA synthesis. This interferes with the generation of DNA copies of viral RNA, which is necessary for the synthesis of new virions. 